\title{
Environmental noise in spawning areas: the case of Atlantic Bluefin Tuna (Thunnus thynnus)
}

\author{
F. Royer ${ }^{1}$ and J.M. Fromentin ${ }^{2}$
}

${ }^{1}$ Large Pelagics Research Lab, Dept. of Zoology, Univ. of New Hampshire, Durham, NH 03824, USA

${ }^{2}$ IFREMER, Centre de Recherche Halieutique Méditerranéen et Tropical, avenue Jean Monnet, BP 171, 34203 Sète cedex, France

\begin{abstract}
:
We here present an exploratory analysis aiming to seek whether the colour of environmental noise theory could help in understanding the intriguing reproductive strategy of Atlantic bluefin tuna (BFT). A frequency-based approach based on spectral exponents, $f$. with $<0$, is chosen and applied on 10 biogeographical provinces covering the North Atlantic. The major BFT spawning area, i.e. the Mediterranean Sea, was the only one to display a pink power spectrum, whereas open ocean regions displayed more reddened fluctuations, i.e. greater variance at low frequencies. Environmental noise in the Mediterranean could, thus, offer more favourable characteristics on the long-term than the open ocean. The implications of these findings are discussed in regards to medium and long (possibly evolutionary) time scales.
\end{abstract}

Keywords: Spawning, environmental noise, spectral analysis, sea surface temperature, Thunnus thynnus 


\section{INTRODUCTION}

The magnitude of environmental stochasticity (i.e. variance in the time domain) has long been recognized as a key factor for understanding population growth and/or extinction in both terrestrial and marine systems (Cushing, 1995, Hjort, 1914, Nisbet \& Gurney, 1982). More recently, Lawton (1988) put forward that the colour of environmental forcing (i.e. variance in the frequency domain) is also a crucial issue. When postulating that reddened noise (i.e. noise with higher variance at low frequencies) could increase population extinction due to a higher probability of consecutive adverse conditions, J.H. Lawton opened an important debate in quantitative ecology. Subsequent studies showed, however, that the mechanisms were more complex than previously thought. The persistence of a population does not solely and directly depend on the colour of environmental noise, but on its interactions with biological processes (Halley, 1996, Morales, 1999, Ripa \& Lundberg, 1996, Petchey et al., 1997). For instance, environmental red noise increases population persistence of overcompensatory population dynamics, but decreases this of undercompensatory ones (and inversely for blue noise, Petchey et al., 1997).

Marine environmental noise is redder than its terrestrial counterpart (Steele, 1985, Vasseur \& Yodzis, 2004). As exploitation reduces population size, fishing could further increase indirectly the risk of extinction of exploited populations through the effects of red noise on depleted populations. The critical situation of the North Sea cod is a good example of this. In the one hand, the long-lasting heavy exploitation has strongly depleted the spawning stock biomass, which is now reduced to a few ageclasses of young adults (ICES, 2004). On the other hand, the recruitment success of this stock is negatively related to temperature (Planque \& Frédou, 1999, O'brien et al., 2000), so that two decades of warmer conditions (i.e. red noise) increased recruitment failures and thus reinforced the depletion of the stock and extinction risk. Most of the exploited marine populations are particularly prone to these phenomena, since they critically depend on their physical habitat during the egg and larvae life stages (Hjort, 1914, Cushing, 1990,Sinclair 1988).

Another facet of this issue relates to the spatial distribution of the spawning grounds of large pelagic fish. Comparing life history traits of tuna, Fromentin and Fonteneau (2001) and Schaefer (2001) pointed out a key difference between tropical and temperate tuna. The former display a long spawning period throughout a wide area (the tropical ocean), whereas the latter exhibit a confined spawning window in both space and time. The mechanism of natal homing has been proposed as a possible explanation, through the imprinting of specific environmental factors at early life stages (Cury 1994) and it has been further developed within the metapopulation concept (Fromentin \& Powers 2005). One may also ask if the maintenance of such a life strategy does not (partially) result from an evolutionary process in relation to the spatial heterogeneity of the environmental forcing. In other words, Atlantic bluefin tuna would only maintain reproduction in confined Mediterranean regions in June (and secondarily in the Gulf of Mexico in May, Fig. 1, see Mather et al., 1995), because the other areas of its wide spatial distribution (i.e. most of the North Atlantic and adjacent seas) would not favour this in respect to their variance in time and frequency domains. To examine this hypothesis, we collected the largest in-situ sea surface temperature (SST) dataset available. We then computed and compared the seasonal cycles, coefficients of variation and spectral properties of several long term time series of SST of the main oceanographic regions of the North Atlantic and adjacent seas.

\section{DATA AND METHOD}

We used the in-situ measurements of the International Comprehensive Ocean-Atmosphere DataSet (ICOADS, http://www.cdc.noaa.gov/). The monthly datasets display a number of geophysical variables at a $2^{\circ} \times 2^{\circ}$ resolution, starting in 1800 . We, however, selected data from the $20^{\text {th }}$ century (1900-2002) to limit spurious sampling variability. For this work, we focused on temperature, a critical factor for growth and survival of eggs and larvae of most fish species, especially for tuna which seldom reproduce under $24^{\circ} \mathrm{C}$ (Schaefer, 2001). For comparison purposes, we considered 10 areas based on the biogeographical provinces defined by Longhurst (1998): 1) the Gulf of Mexico and Caribbean Sea (CARB), 2) the western part of the sub-tropical gyre (NASTW), 3) the Gulf Stream region (GFST), 4) the northern Gulf Stream extension (NADR) 5), the eastern part of the sub-tropical gyre (NASTE), 6) the Mediterranean Sea (MEDI), 7) the Canary province (CNRY), 8) the northern part of the tropical gyre (NATR), 9) the western tropical province (WTRA), and 10) its eastern counterpart (ETRA, Fig. 1).

The number of SST observations was homogeneous between months within each province, with an average of 134770 samples (st. dev. 46580), except for the more restricted Canary region with 5790 samples on average (st. dev. 470). To characterize patterns of SST in the frequency 
domain, we followed Mandelbrot (1983) and Halley (1996), who showed that a wide range of 'noises' in nature can be described by the inverse power law, $f$ (where $<0$ and $f$ is the frequency). is thus a synthetic measure of the frequency composition of a time series, defined as the slope of the regression of the $\log _{10}$ spectral densities against the $\log _{10}$ frequencies (Vasseur \& Yodzis, 2004): higher the absolute value of the slope, higher the degree of autocorrelation. White noise corresponds to the special case for which $=0$ and can be seen as stochastic variations around a fixed mean. = -1 corresponds to red noise, i.e. signals dominated by low frequencies or long-term fluctuations (Vasseur \& Yodzis, 2004). < - -1 correspond to darker or more "coloured" noises (more autocorrelated time series), i.e. $\quad=-2$ for brownian noise and $=-3$ for black noise. The monthly aggregation induced a cut-off in the frequency spectrum and decreased the effects of weekly and daily variability, but this was not considered critical as BFT spawning usually occurs over 1 to 2 months (Mather et al., 1995). Prior to spectral analysis, the seasonal component was further removed by subtracting a 12month anomaly from each series (Chatfield, 1989). A Parzen window was then applied to the raw periodogram to correct for inconsistency, as in Priestley (1981). Francois, je te propose de retirer cette dernière phrase, car en voyant les corrections de Brian, je m'apercois que les gens font facilement des confusions sur ce que l'on appelle les séries de janvier, février, etc.. avec séries mensuels...

\section{RESULTS}

Considering that BFT (as all tuna species) needs warm waters to reproduce $\left(>24^{\circ} \mathrm{C}\right.$, Schaefer, 2001) and that BFT reproduction occurs in May-June, absolute values of temperatures appear limiting in 3 of 10 provinces, i.e. NADR, GFST and NASTE (Fig. 2a). The coefficients of variation (CV) of the raw SST time series of the 10 oceanographic regions range between $20 \%$ (WTRA, CARB and NATR) and 70\% (GFST) and mostly reflect the strength of the seasonal variability of the SST (being higher in temperate regions than in the tropical and sub-tropical ones, Fig. 1). The power spectra of the 10 SST time series, from which the seasonal components have been removed, are given in Fig. 1 together with the corresponding . values. The $s$ vary greatly from one area to another, from -0.62 (MEDI) to -1.20 (NATR). SST of the 7 main North Atlantic regions (i.e. NASTW, GFST, NADR, NASTE, NATR, WTRA and ETRA) are characterized by typical red noises (. $\cong-1)$. In these areas, variations in SST are dominated by low frequencies. The main BFT spawning area (MEDI) displays the flattest SST spectrum ( . . -0.62), i.e. variations are more balanced between high and low frequencies (Fig. 1). SST in CARB and CNRY are intermediate (. . - 0.72 and -0.86). In other words, MEDI, and secondarily CNRY and CARB, display a larger range of frequencies (especially more short-term variability) than the 7 oceanic regions of the North Atlantic (which are more variable on the long-term). The examination of the month-by-month time series of the 10 regions reproduces the seasonal cycle (Fig. 2A) and reveals that NADR, MEDI and CNRY are characterized by even flatter SST spectra during spring, with . between -0.2 and -0.5 (Fig. 2B). During the BFT spawning season, the signals are, thus, even closer to white noise (with almost as much high as low frequencies) in these 3 areas. CARB also displays a lower in May, when BFT spawning occurs in this area.

\section{DISCUSSION}

MEDI, which is the main spawning ground for Atlantic bluefin tuna (Ravier \& Fromentin, 2001, Mather et al., 1995), displayed the flattest spectrum of all provinces. The SST variability of this area, and secondarily of CNRY and CARB, tends to have a pink spectrum, while the SST fluctuations in the open ocean are more reddened. This complies with the paradigm in physical oceanography postulating that oceanic processes smooth atmospheric white noise (Hasselmann, 1976, Steele, 1985, Steele, 1989). As such, the characteristic time scale (or inertia) of an oceanic basin is related to its size and sensitivity to climate: confined basins are more subject to atmospheric forcing and thus display flatter variance spectra. This is not an indication of long-term invariance, as shown by the high $\mathrm{CV}$ in the Mediterranean, but rather an indication of a greater range of time frequencies. The Mediterranean Sea can thus be perceived as a "miniature ocean", where all the major physical mechanisms occur. A reproductive strategy in the Mediterranean Sea could thus offer to BFT more spatio-temporal options per unit area than oceanic regions. In other words, spawning in a short temporal window in enclosed basins could led to higher survival of offspring than in oceanic regions; a feature that is apparently maintained through natal homing (i.e. imprinting of environmental cues 
during early stages). Note that tropical regions (WTRA and ETRA), where tropical tuna inhabit and spawn over long periods and large areas (Fromentin and Fonteneau, 2001), clearly display redder spectra, a result that is consistent with the above conclusion.

Furthermore, bluefin tuna is a long-lived species that includes numerous reproductive ageclasses, so that its dynamics is comparatively resistant to accidents or short-term fluctuations in recruitment (Fromentin \& Fonteneau, 2001). Such life history traits also make that the environmental stochasticity taking place during the reproduction is echoed through the life cycle and generates longterm fluctuations in its spawning stock biomass (Bjornstad et al., 2004). In other words, bluefin tuna life cycle acts as a low pass-filter and reddens environmental noise (as opposed to tropical tuna, see Fromentin \& Fonteneau, 2001). This feature is also in agreement with the hypothesis that red environmental noise is unfavourable for bluefin tuna.

We are aware that this analysis is preliminary and cannot give firm conclusions about bluefin tuna reproductive strategy. Our purpose was firstly to draw attention to the fruitfulness, in a fisheries ecology perspective, of an exploratory approach based on the analysis of geophysical datasets. Further work is obviously needed, e.g. to investigate the spawning grounds at finer scales and the use of other environmental factors. While temperature is indeed the most studied geophysical variable, turbulence and retention are also known to be critical for the survival of fish eggs and larvae (Sinclair 1988). Collecting or reconstructing time series of these indices implies tedious work, but could provide new insights on the reproductive strategy of many pelagic species (Agostini \& Bakun, 2002). The colour of environmental noise in marine population dynamics is a fundamental problem, which can be discussed in the light of both life history traits and evolutionary issues. 


\section{REFERENCES}

Agostini V., Bakun A. (2002) Ocean triads' in the Mediterranean Sea: physical mechanisms potentially structuring reproductive habitat suitability (with example application to European anchovy, Engraulis encrasicolus). Fish. Oceanogr. 11:128-142.

Bjornstad O., Nisbet R., Fromentin J.-M. (2004) Trends and cohort resonant effects in age-structured populations. J. Anim. Ecol. 73:1157-1167.

Chatfield C. (1989) The analysis of times series: an introduction. London: Chapman \& Hall.

Cury P., (1994) Obstinate nature: An ecology of individuals. Thoughts on reproductive behaviour and biodiversity. Can. J. Fish. Aquat. Sci. 51:1664-1673.

Cushing D.H. (1990) Plankton production and year class strength in fish populations: an update of the match/mismatch hypothesis. Adv. Mar. Biol. 26:249-293.

Cushing D.H. (1995) Population production and regulation in the sea: a fisheries perspective, Cambridge: Cambridge University Press.

Fromentin J.-M., Fonteneau A. (2001) Fishing effects and life history traits: a case-study comparing tropical versus temperate tunas. Fish. Res. 53:133-150.

Fromentin J.-M., J.E. Powers. 2005. Atlantic bluefin tuna: population dynamics, ecology, fisheries and management. Fish Fish. 6: 281-306.

Halley J.M. (1996) Ecology, evolution, and 1/f noise. Trend Ecol. Evol. 11:33-37.

Hasselmann K. (1976) Stochastic climate models I: theory. Tellus 28:473-485.

Hjort J. (1914) Fluctuations in the great fisheries of northern Europe. Viewed in the light of biological research. Rapp. P.-v. Réun. Cons. int. Explor. mer 20:1-228.

ICES (2004) Report of the ICES Advisory Committee on Fishery Management and Advisory Committee on Ecosystems. Vol. 1, Num. 2, Copenhagen.

Lawton J.H. (1988) More time means more variations. Nature 334:563.

Longhurst A. (1998) Ecological Geography of the sea. London: Academic Press.

Mandelbrot B.B. (1983) The fractal geometry of nature. San Francisco: W.H. Freeman.

Mather F.J., Mason Jr J.M., Jones A. (1995) Historical document: life history and fisheries of Atlantic bluefin tuna. NOAA Technical Memorandum NMFS-SEFSC-370. Miami, 165 p.

Morales J.M. (1999) Viability in a pink environment: why "white noise" models can be dangerous. Ecol. Lett. 2:228-232.

Nisbet R.M., Gurney W.S.C. (1982) Modelling fluctuating populations. Chichester: Wiley 
O'Brien C.M., Fox C.J., Planque B., Casey J. (2000) Climate variability and North Sea cod. Nature 404:142.

Petchey L.G., Gonzalez A., Wilson H.B. (1997) Effects on population persistence: the interaction between environmental noise colour, intraspecific competition and space. Proc. Roy. Soc. London, Ser.B 264:1841-1847.

Planque B., Frédou T. (1999) Temperature and the recruitment of Atlantic cod (Gadus mohrua). Can. J. Fish. Aquat. Sci. 56:2069-2077.

Priestley M.B. (1981) Spectral analysis and times series. London: Academic Press.

Ravier C., Fromentin J.-M. (2001) Long-term fluctuations in the Eastern Atlantic and Mediterranean bluefin tuna population. ICES J. Mar. Sci. 58:1299-1317.

Ripa J., Lundberg P. (1996) Noise colour and the risk of extinctions. Proc. Roy. Soc. London, Ser.B 263:1751-1753.

Schaefer K.M. (2001) Reproductive biology of tunas. In: Tuna Physiology, ecology, and evolution. B.A. Block \& E.D. Stevens (eds) San Diego: Academic Press, pp 225-270.

Sinclair, M. (1988). Marine populations: An essay on population regulation and speciation. Seattle: Washington Sea Grant.

Steele J.H. (1985) A comparison of terrestrial and marine ecological systems. Nature 313:355-358.

Steele J.H. (1989) The ocean "landscape". Landscape Ecol. 3:185-192.

Vasseur D.A., Yodzis P. (2004) The color of environmental noise. Ecology 85:1146-1152. 


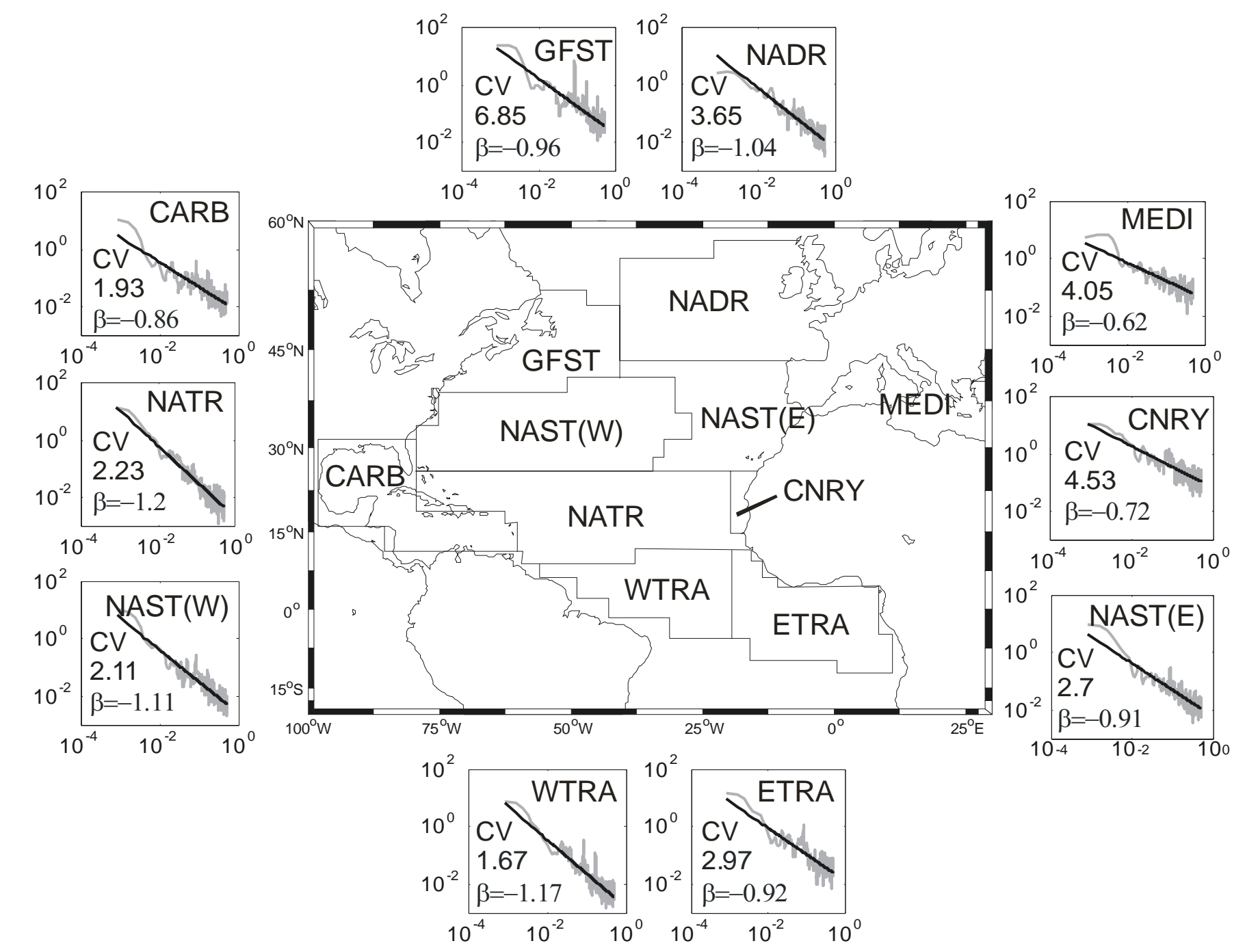

Figure 1. Map of the distribution of Atlantic bluefin tuna in the North Atlantic and adjacent seas with its known migration routes and spawning areas; the ten biogeographical regions used in this study are superimposed. The CV, the spectrum (log-log scale) and associated of the 1900-2002 time series of COADS Sea Surface Temperature are depicted for each province. 
A.

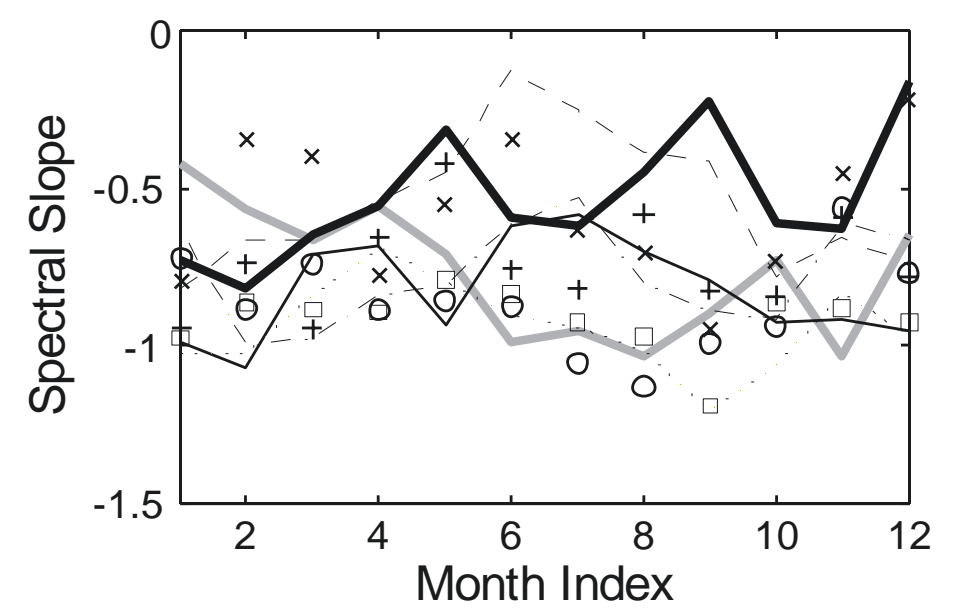

B.

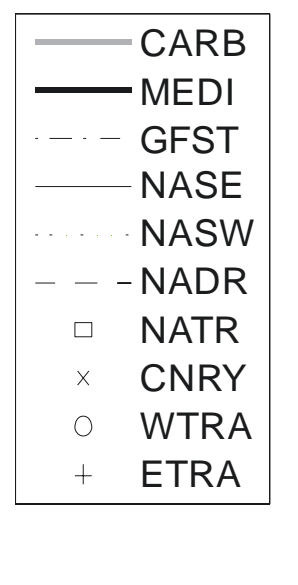

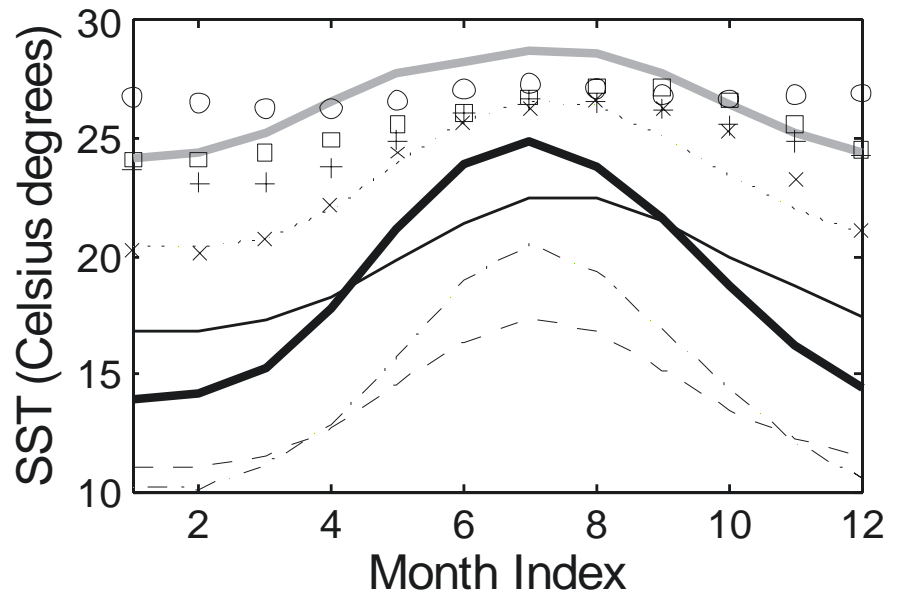

Figure 2. Montly SST values (2a) and coefficients (2b) for the ten biogeographical regions: the Gulf of Mexico and Caribbean Sea (CARB), the western part of the sub-tropical gyre (NASTW), the Gulf Stream area (GFST), the northern Gulf Stream extension (NADR), the eastern part of the sub-tropical gyre (NASTE), the Mediterranean Sea (MEDI), the canarian province (CNRY), the northern part of the tropical gyre (NATR), the western tropical province (WTRA) and its eastern counterpart (ETRA). 